\title{
Glutathione Transferase in Bacteria: Subunit Composition and Antigenic Characterization
}

\author{
By RAFFAELE PICCOLOMINI, ${ }^{*}$ CARMINE DI ILIO, ${ }^{2}$ \\ ANTONIO ACETO, ${ }^{2}$ NERINO ALLOCATI, ${ }^{1}$ ANGELO FARAONE, 1 \\ LUIGINA CELLINI, ${ }^{1}$ GIAMPIETRO RAVAGNAN ${ }^{3}$ \\ AND GIORGIO FEDERICI ${ }^{3}$ \\ ${ }^{1,2}$ Istituto di Medicina Sperimentale, Cattedra di Microbiologia ${ }^{1}$, e Istituto di Scienze \\ Biochimiche ${ }^{2}$, Facoltà di Medicina, Università 'G. D'Annunzio', Via dei Vestini, \\ 66100 Chieti, Italy \\ ${ }^{3}$ Dipartimento di Biologia, Università di Roma 'Tor Vergata', Roma, Italy
}

(Received 17 April 1989; revised 14 June 1989; accepted 18 July 1989)

The presence of glutathione transferase (GST; EC 2.5.1 18) in Escherichia coli ATCC 25922, E. coli ATCC 25422, Proteus vulgaris ATCC 8427, Pseudomonas aeruginosa ATCC 27853, Klebsiella oxytoca CIP 666, $K$. oxytoca AF 101, Enterobacter cloacae CIP 6085, Serratia marcescens CIP 6755, and Proteus mirabilis AF 2924 was investigated. Using 1-chloro-2,4dinitrobenzene as substrate, GST activity was found in the glutathione- (GSH-) affinity-purified fraction of all strains tested. SDS-PAGE analysis of GSH-affinity-purified enzyme indicated that the GSTs of all these bacteria are dimers of two identical subunits of $M_{\mathrm{r}}$ about 22500 . Rabbit antiserum directed against the major isoenzyme present in Proteus mirabilis AF 2924, Pm-GST-6.0, was used to investigate the antigenic properties of bacterial GSTs. Western blot analysis indicated that a GST antigenically identical to Pm-GST-6.0 is present in Enterobacter cloacae CIP 6085, Escherichia coli ATCC 25422 and Proteus vulgaris ATCC 8427, but absent in Escherichia coli ATCC 25922, Klebsiella oxytoca CIP 666, K. oxytoca AF 101 and Serratia marcescens CIP 6755. The presence of Pm-GST-6.0, but not mammalian GST, increased the MIC values of amikacin, ampicillin, cefotaxime, cephalothin and nalidixic acid for $E$. coli ATCC 25922. It is suggested that bacterial GST may represent a defence against the effects of antibiotics.

\section{INTRODUCTION}

Glutathione transferases (GSTs; EC 2.5.1.18) are a family of multifunctional proteins that catalyse the conjugation of glutathione (GSH) to the electrophilic centre of a large number of active molecules (Awasthi \& Singh, 1985; Chasseaud, 1979; Jacoby \& Habig, 1980; Ketterer, 1986; Mannervik, 1985; Mannervik \& Danielson, 1988). GSTs can probably also function as intracellular transport and binding proteins by virtue of their capacity to bind covalently or noncovalently a wide number of hydrophobic compounds such as bilirubin, haem, drugs, steroid hormones, bile acids and other xenobiotics including carcinogens (Jakoby \& Habig, 1980; Kamisaka et al., 1975a, $b$; Mannervik \& Danielson, 1988; Maruyama et al., 1983; Smith \& Litwack, 1980; Takikawa et al., 1986). In general they are thought to play a key role in detoxification processes. GSTs have been most extensively studied in man, rat and mouse, in which multiple isoforms all composed of two subunits are present (Awasthi \& Singh, 1985; Jakoby \& Habig, 1980; Ketterer, 1986; Mannervik, 1985; Mannervik \& Danielson, 1988). By

Abbreviation: GST, glutathione transferase. 
the use of various substrates, inhibitors, SDS-PAGE and antisera, and by determining the Nterminal amino acid sequences, it was proposed that the cytosolic GSTs of rat, mouse and man should be grouped into at least three distinct families: alpha, mu and pi (Mannervik et al., 1985). GSTs have also been purified from fish (Ramage et al., 1986) and insects (Clark et al., 1986; Cochrane et al., 1987), and have been studied in a number of micro-organisms (Casalone et al., 1988; Di Ilio et al., 1988a; Kumagai et al., 1988; Lau et al., 1980). A GST composed of two subunits of $M_{\mathrm{r}} 22000$ has been isolated from the fungus Mucor javanicus (Ando et al., 1988). Two structurally and antigenically distinct GSTs have been recently purified and characterized from the yeast Issatchenkia orientalis (Tamaki et al., 1989). However, very little information is available on the presence, the subunit composition, the antigenic properties and the role of bacterial GSTs.

We have recently purified and characterized an isoenzyme of GST from Proteus mirabilis AF 2924 (Pm-GST-6.0) (Di Ilio et al., 1988a) having structural and antigenic properties which distinguished it from the GSTs characterized from mammalian sources. In the present study, by using a GSH-affinity-purification technique, the amount of GSTs in several bacterial strains was estimated and, by using antiserum raised against Pm-GST-6.0, the presence of an antigenically similar GST in several other bacterial strains was investigated. To better understand the role of bacterial GST, we studied the binding capacity of Pm-GST-6.0 to several antibiotics, and determined the effect of Pm-GST-6.0 on their MIC values.

\section{METHODS}

Bacterial strains. These were as follows: Escherichia coli ATCC (American Type Culture Collection) 25922, E. coli ATCC 25422, Proteus vulgaris ATCC 8427, Pseudomonas aeruginosa ATCC 27853, Klebsiella oxytoca CIP (Collection of the Institut Pasteur) 666, Enterobacter cloacae CIP 6085, Serratia marcescens CIP 6755, and Klebsiella oxytoca AF 101 and Proteus mirabilis AF 2924 of the Type Culture Collection of the Institute of Experimental Medicine, Chieti, Italy. All strains were stored at $-70^{\circ} \mathrm{C}$, and fresh subcultures were regrown in sterile Mueller-Hinton broth (MH broth; BBL).

Antimicrobial agents. The antibiotics were obtained as follows: amikacin, Bristol Italiana (Latina, Italy); cefotaxime, Hoechst Italia (L'Aquila, Italy); ampicillin, Beecham, cephalothin and nalidixic acid, Sigma. Nalidixic acid was initially dissolved in $0 \cdot 1 \mathrm{M}-\mathrm{NaOH}$ and subsequently diluted in $\mathrm{MH}$ broth. Amikacin, ampicillin and cephalosporins were prepared in distilled water and sterilized by membrane filtration. Fresh dilutions of each compound were prepared daily and according to the manufacturers' instructions.

Preparation of cell-free extracts and GSH-affinity purification. Washed cells were grown aerobically for $18 \mathrm{~h}$ at $37^{\circ} \mathrm{C}$ in Trypticase Soy Broth (BBL), suspended in $10 \mathrm{~mm}$-potassium phosphate buffer, $\mathrm{pH} \mathrm{7.0} \mathrm{(buffer} \mathrm{A),} \mathrm{and}$ disrupted by sonication (five bursts of $3 \mathrm{~min}$ each, at $300 \mathrm{~W}$ ) with a Labsonic 1510 (Braun) sonicator. The particulate material was removed by centrifugation at $105000 \mathrm{~g}$ for $1 \mathrm{~h}$ and the supernatant applied to a GSHSepharose affinity column $(1 \mathrm{~cm} \times 10 \mathrm{~cm})$ (Simmons \& Van der Jagt, 1981) pre-equilibrated with buffer A. The column was exhaustively washed with buffer A supplemented with $50 \mathrm{mM}-\mathrm{KCl}$. The enzyme was eluted with $50 \mathrm{~mm}-\mathrm{Tris} / \mathrm{HCl}$ buffer, $\mathrm{pH} 9.6$, containing $5 \mathrm{~mm}-\mathrm{GSH}$. The fractions showing GST activity were pooled, concentrated by ultrafiltration, dialysed against buffer A supplemented with $1 \mathrm{~mm}$-dithiothreitol and used for further studies.

$S D S-P A G E$. SDS-PAGE in discontinuous slab gels was done by the method of Laemmli (1970). The SDS concentration was $0 \cdot 1 \%(\mathrm{w} / \mathrm{v})$, and the spacer and the separating gels contained $3 \%$ and $12.5 \%(\mathrm{w} / \mathrm{v})$ acrylamide respectively. Bovine serum albumin $\left(M_{\mathrm{r}} 66000\right)$, ovalbumin $\left(M_{\mathrm{r}} 45000\right)$, glyceraldehyde-3-phosphate dehydrogenase $\left(M_{\mathrm{r}} 36000\right)$, carbonic anhydrase $\left(M_{\mathrm{r}} 29000\right)$, trypsinogen $\left(M_{\mathrm{r}} 24000\right)$, soybean trypsin inhibitor $\left(M_{\mathrm{r}} 20100\right)$ and $\alpha$-lactalbumin $\left(M_{\mathrm{r}} 14200\right)$ were used as standards for determination of subunit molecular size.

Antiserum. Antiserum against Pm-GST-6.0 (an isoenzyme of GST from Proteus mirabilis AF 2924) was raised in rabbits via two injections of $100 \mu \mathrm{g}$ protein in Freund's complete adjuvant and was the same as that used by us previously (Di Ilio et al., 1988a).

Assay of GST activity. This was done as described by Habig \& Jakoby (1981) using 1 mM-1-chloro-2,4dinitrobenzene and $2 \mathrm{mM}-\mathrm{GSH}$. Protein concentrations were determined by the method of Bradford (1976) with $\gamma$ globulin (Bio-Rad) as standard.

Immunoblot analysis. Proteins were electrophoretically transferred from polyacrylamide gels onto nitrocellulose membranes (Bio-Rad Transblot System) according to the method of Towbin et al. (1979). Electroblotting was done for $16 \mathrm{~h}$ at $30 \mathrm{~V}$ in $25 \mathrm{~mm}$-Tris base/192 mM-glycine, $\mathrm{pH} \mathrm{8.3,} \mathrm{containing} 20 \%(\mathrm{v} / \mathrm{v})$ methanol. All incubations were for $1 \mathrm{~h}$ at $25^{\circ} \mathrm{C}$ with intermediate rinses in $50 \mathrm{~mm}$-Tris base buffer, $\mathrm{pH} 7.5,400 \mathrm{mM}-\mathrm{NaCl}$ (buffer B) containing $0.05 \%$ Tween 20 (buffer C). Non-specific binding was blocked by placing membranes in buffer B supplemented 
with $3 \%(w / v)$ bovine serum albumin. Membranes were incubated with primary antiserum (antiserum raised against Pm-GST-6.0 at optimum dilution, 1:250), in buffer B containing 3\% bovine serum albumin. The membranes were washed with buffer $\mathrm{C}$ and then incubated for $1 \mathrm{~h}$ at room temperature, with gentle shaking, in the same buffer containing $1 \%(\mathrm{w} / \mathrm{v})$ gelatin and a horseradish peroxidase-conjugated goat anti-rabbit IgG (BioRad) diluted 1:3000. After treatment with peroxidase-conjugated antibody, the membranes were washed three times in buffer $\mathrm{C}$ ( $5 \mathrm{~min}$ each) and twice in buffer B, then immersed in development solution ( $100 \mathrm{ml}$ buffer $\mathbf{B}$ containing $60 \mathrm{mg}$ 4-chloro-1-naphthol (Bio-Rad) and $60 \mu \mathrm{l} 30 \% \mathrm{H}_{2} \mathrm{O}_{2}$ ). The blot was then washed once with distilled water, air-dried and photographed.

Binding of antibiotics to Pm-GST-6.0. This was determined by following the quenching of the intrinsic tryptophan fluorescence upon addition of drugs. Measurements were made in $10 \mathrm{~mm}$-potassium phosphate buffer, pH 7.0, using an Aminco Bowman spectrofluorometer. The decrease in the intrinsic fluorescence upon addition of antibiotic was measured at $350 \mathrm{~nm}$ while exciting at $280 \mathrm{~nm}$, with a slit width of $3 \mathrm{~nm}$. The absorbance of solutions with antibiotics was sufficiently low that correction for inner filter effects were of minor significance; correction was made for dilution. Dissociation constants $\left(K_{\mathrm{D}}\right)$ were calculated from a plot of the reciprocal of the change in fluorescence $(\Delta F)$ against the reciprocal of the total ligand concentration. Enzyme concentration was $1 \mu \mathrm{M}$.

Determination of minimal inhibitory concentrations (MICs). These tests were done in 96-well microtitre trays, using a Titertek manual multidiluter (Flow Laboratories) for dispensing and inoculating $100 \mu \mathrm{l}$ volumes of $\mathrm{MH}$ broth containing doubling dilutions of each antibiotic (range 32-0.06 $\mu \mathrm{g} \mathrm{ml}^{-1}$; except cefotaxime, for which the range was $0 \cdot 015-8 \mu \mathrm{g} \mathrm{ml}^{-1}$ ). For amikacin, the medium was supplemented with calcium and magnesium ions (National Committee for Clinical Laboratory Standards, 1983). The volume of the inoculum was $100 \mu$, with a final bacterial concentration of $5 \times 10^{5} \mathrm{c.f}$.u. $\mathrm{ml}^{-1}$. The wells were inoculated simultaneously with a Titertek multicanal pipette, 50-200 $\mu$ l (Flow Laboratories). The drug dilutions with enzyme (Pm-GST-6.0) were done as described above, mixing $50 \mu \mathrm{l}$ volumes of $\mathrm{MH}$ broth containing four times the final concentration of antibiotic (range $512-0.015 \mu \mathrm{g} \mathrm{ml}^{-1}$ ), $50 \mu \mathrm{l}$ enzyme, and $100 \mu \mathrm{l}$ bacterial inoculum. The 96-well microtitre trays were incubated at $37^{\circ} \mathrm{C}$ for $18 \mathrm{~h}$. The MIC is defined as the lowest concentration of antimicrobial agent that inhibited the development of visible growth in the well. .

\section{RESULTS}

\section{Purification of GST}

Table 1 shows the GST activity values toward 1-chloro-2,4-dinitro-benzene and the percentage of enzyme obtained after purification by GSH-affinity column in several bacterial strains; no measurable activity appeared in the column void volume, suggesting that all enzymes remained bound to the column. It has to be noted that the activity values reported for bacteria are much lower than those found in mammalian tissues (Di Ilio et al., 1986, 1988 b; Del Boccio et al., 1987; Kamisaka et al., 1975a; Ketterer, 1986; Mannervik et al., 1985). Relatively high activity was found in Klebsiella oxytoca AF 101, K. oxytoca CIP 666 and Enterobacter cloacae CIP 6085. Serratia marcescens CIP 6755 showed the lowest activity. Intermediate values were found in Proteus vulgaris ATCC 8427, Escherichia coli ATCC 25422, E. coli ATCC 25922, Pseudomonas aeruginosa ATCC 27853 and Proteus mirabilis AF 2924.

Table 1. GST activity in several bacterial strains after affinity chromatography and percentage of protein retained on the affinity column and eluted by $5 \mathrm{mM}-G S H$

\section{Strain}

Klebsiella oxytoca AF 101

Klebsiella oxytoca CIP 666

Enterobacter cloacae CIP 6085

Proteus vulgaris ATCC 8427

Escherichia coli ATCC 25422

Proteus mirabilis AF 2924

Escherichia coli ATCC 25922

Pseudomonas aeruginosa ATCC 27853

Serratia marcescens CIP 6755

Rat liver

Human liver

Mouse liver
Activity

$[\mu \mathrm{mol} \mathrm{min}-1$

(mg protein $)^{-1}$ ]

$4 \cdot 80$

$4 \cdot 18$

3.47

1.47

$1 \cdot 01$

0.79

0.76

0.74

0.435

$16 \cdot 1$

$18 \cdot 1$

$86 \cdot 2$
Protein

$(\%)$

0.007

0.01

0.05

0.04

0.003

0.06

0.01

0.002

0.04

4.6

$2 \cdot 7$

$3 \cdot 7$ 


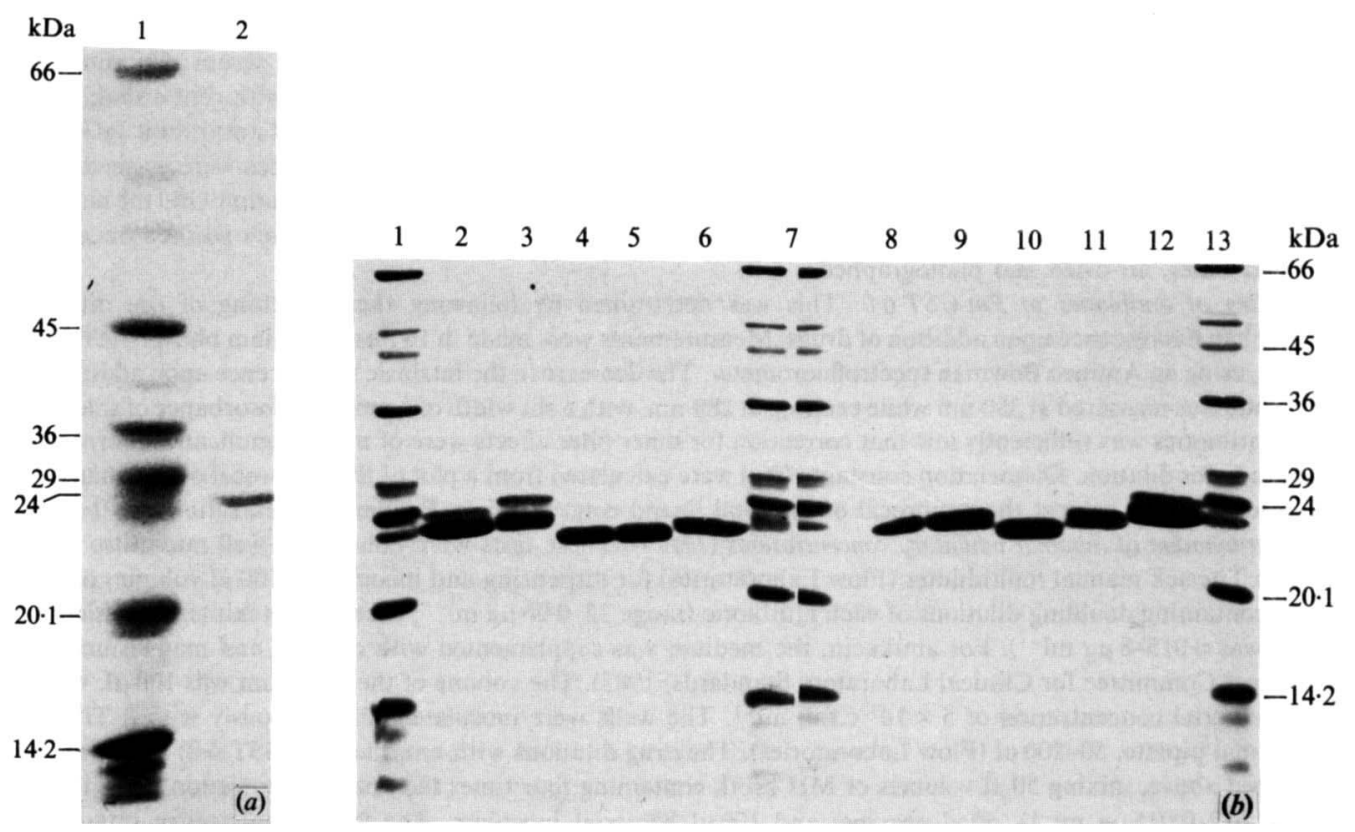

Fig. 1. (a) Slab SDS-PAGE of purified Pm-GST-6.0. Lane 1, standards and their $M_{\mathrm{r}}$ values, from top to bottom, are: bovine serum albumin $(66,000)$, ovalbumin $(45,000)$, glyceraldehyde-3-phosphate dehydrogenase $(36,000)$, carbonic anhydrase $(29,000)$, trypsinogen $(24,000)$, soybean trypsin inhibitor $(20,100), \alpha$-lactalbumin $(14,200)$; lane 2, Pm-GST-6.0. (b) Slab SDS-PAGE of GSH-affinity-purified GST from several bacterial strains. Lanes 1, 7 and 13, standards; lanes 2 and 12, mouse GSTs; lane 3, rat GST; lane 4, Klebsiella oxytoca AF 101; lane 5, K. oxytoca CIP 666; lane 6, Proteus vulgaris ATCC 8427; lane 8, Escherichia coli ATCC 25422; lane 9, E. coli ATCC 25922; lane 10, Serratia marcescens CIP 6755; lane 11, Enterobacter cloacae CIP 6085.

\section{$M_{\mathrm{r}}$ and subunit composition}

The results of SDS-PAGE of GSH-affinity-purified GST from several bacterial strains are shown in Fig. 1. Duplicate experiments with two different enzyme preparations gave essentially the same results. A single polypeptide band was obtained in all the preparations, indicating the absence of contaminating proteins. For comparison, rat and mouse liver GSTs were included in the gel shown in Fig. $1(b)$. All the bacterial GSTs migrated slightly faster than the mammalian GSTs. On the basis of their relative electrophoretic mobilities the GSTs investigated can be divided in two groups. The GSTs of Proteus mirabilis AF 2924, Proteus vulgaris ATCC 8427, Escherichia coli ATCC 25422, E. coli ATCC 25922 and Enterobacter cloacae CIP 6085 migrated more slowly than the others, suggesting that the subunits of these enzymes have an $M_{\mathrm{r}}(22500)$ slightly higher than that of Klebsiella oxytoca AF 101, K. oxytoca CIP 666 and Serratia marcescens CIP $6755(22000)$. As the approximate $M_{\mathrm{r}}$ of the bacterial GSTs, as determined by gel filtration on Sephadex G-100, was 50000 (data not presented), the results of Fig. 1 indicate that the bacterial GSTs studied are all dimeric proteins composed of two subunits with the same $M_{\mathrm{r}}$.

\section{Antigenic studies}

We have recently purified and characterized from Proteus mirabilis AF 2924 an isoenzyme of GST with acid properties (pI 6.0) (Di Ilio et al., 1988a). This enzyme (Pm-GST-6.0) has several characteristics that distinguish it from all GSTs purified from mammalian sources. In particular, none of the antisera raised against numerous rat, mouse and human GSTs crossreacted in immunodiffusion and immunoblotting experiments with this bacterial enzyme. On the other hand, identical results were obtained when anti-Pm-GST-6.0 serum was tested with human, rat and mouse isoenzymes (Di Ilio et al., 1988a). To explore whether Pm-GST-6.0 is a 


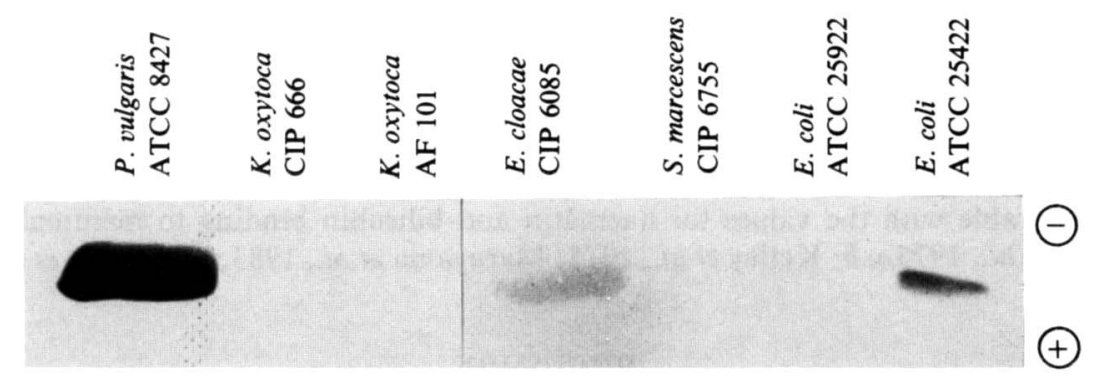

Fig. 2. Western blot analysis of GSH-affinity-purified GST of seven bacterial strains using antibodies raised against Pm-GST-6.0.

protein specific to Proteus mirabilis AF 2924 or is also present in other bacterial strains, the enzymes of Klebsiella oxytoca AF 101, $K$. oxytoca CIP 666, Proteus vulgaris ATCC 8427, Escherichia coli ATCC 25422, E. coli ATCC 25922, Serratia marcescens CIP 6755 and Enterobacter cloacae CIP 6085 recovered from GSH-affinity chromatography were subjected to SDS-PAGE and then transblotted on to nitrocellulose filter and tested against the antiPm-GST-6.0 serum (Fig. 2). Only the GSTs of Proteus vulgaris ATCC 8427, Escherichia coli ATCC 25422 and Enterobacter cloacae CIP 6085 cross-reacted with anti-Pm-GST-6.0 serum; no cross-reaction was seen with the GSTs of the other four strains tested, suggesting that Pm-GST-6.0 is not ubiquitously present in the strains examined.

\section{Interaction with antibiotics}

The effects of Pm-GST-6.0 on the antimicrobial activity of several antibiotics are reported in Table 2. Quadruplicate experiments with at least two different enzyme preparations gave essentially the same results. In the presence of Pm-GST-6.0 the MIC values for amikacin, ampicillin, cefotaxime, cephalothin and nalidixic acid were significantly increased (two to eight times the control values). This property was specific for bacterial GST, as no effects were seen in the presence of mammalian GSTs or other binding proteins such as human serum albumin.

Table 2. Effect of Pm-GST-6.0 on the antimicrobial activity (MIC) of several antibiotics against Escherichia coli ATCC 25922

The minimal inhibitory concentration (MIC) is defined as the lowest concentration of antimicrobial agent that inhibited the development of visible growth in the well. MIC values are from quadruplicate experiments with at least two different enzyme preparations. AK, Amikacin; AMP, Ampicillin; CTX, Cefotaxime; KF, Cephalothin; NAL, Nalidixic acid. The concentrations of proteins used are given in parentheses.

\begin{tabular}{|c|c|c|c|c|c|}
\hline \multirow[b]{2}{*}{ Protein in assay } & \multicolumn{5}{|c|}{$\operatorname{MIC}\left(\mu \mathrm{g} \mathrm{ml}^{-1}\right)$} \\
\hline & AK & AMP & CTX & $\mathbf{K F}$ & NAL \\
\hline Control & 1 & 2 & 0.03 & 4 & 2 \\
\hline $\begin{array}{l}\text { Human serum albumin } \\
\left(2 \cdot 5-100 \mu \mathrm{g} \mathrm{ml}^{-1}\right)\end{array}$ & 1 & 2 & 0.03 & 4 & 2 \\
\hline $\begin{array}{l}\text { Mouse GST MI } \\
\quad\left(2 \cdot 5-100 \mu \mathrm{g} \mathrm{ml}^{-1}\right)\end{array}$ & 1 & 2 & 0.03 & 4 & 2 \\
\hline $\begin{array}{l}\text { Mouse GST MII } \\
\quad\left(2 \cdot 5-100 \mu \mathrm{g} \mathrm{ml}^{-1}\right)\end{array}$ & 1 & 2 & 0.03 & 4 & 2 \\
\hline Pm-GST-6.0 & & & & & \\
\hline$\left(5 \mu \mathrm{g} \mathrm{ml}^{-1}\right)$ & 1 & 2 & 0.03 & 4 & 2 \\
\hline$\left(10 \mu \mathrm{g} \mathrm{ml}^{-1}\right)$ & 1 & 2 & 0.03 & 4 & 32 \\
\hline$\left(20 \mu \mathrm{g} \mathrm{ml}^{-1}\right)$ & 1 & 4 & 4 & 8 & 64 \\
\hline$\left(30 \mu \mathrm{g} \mathrm{ml}^{-1}\right)$ & 8 & 8 & 4 & 8 & 256 \\
\hline$\left(40 \mu \mathrm{g} \mathrm{ml}^{-1}\right)$ & 128 & 8 & 4 & 8 & 512 \\
\hline$\left(50 \mu \mathrm{g} \mathrm{ml}^{-1}\right)$ & 128 & 8 & 4 & 8 & 512 \\
\hline$\left(100 \mu \mathrm{g} \mathrm{ml}^{-1}\right)$ & 256 & 8 & 4 & 8 & 512 \\
\hline
\end{tabular}


The binding capacity of four antibiotics to Pm-GST-6.0 was determined by the quenching of the intrinsic tryptophan fluorescence. The dissociation constants obtained were as follows: cephalothin, $207 \mathrm{nM}$; ampicillin, $309 \mathrm{nM}$; amikacin, $434 \mathrm{nM}$; cefotaxime, $2400 \mathrm{nM}$. These results indicate that all the drugs tested have a high affinity for the bacterial GST. It is interesting that the dissociation constants for the binding of antibiotics to bacterial GST are quite comparable with the values for haematin and bilirubin binding to mammalian GSTs (Kamisaka et al., 1975a, b; Ketley et al., 1975; Maruyama et al., 1983; Takikawa et al., 1986).

\section{DISCUSSION}

The data presented here prove that GSTs are present in several bacterial strains. These results are of particular interest as until recently the presence of GSTs in bacteria was uncertain (Lau et $a l ., 1980)$. This was probably due to the limited number of strains investigated or to difficulties in testing the GSH conjugating activity in their cytosol fractions. In the bacterial strains investigated here, GST ranged from $0.002 \%$ of total cytosolic proteins for Pseudomonas aeruginosa ATCC 27853 to $0.06 \%$ for Proteus mirabilis AF 2924. These values are much lower than those $(2-5 \%)$ found for GSTs of mammalian tissues (Jakoby \& Habig, 1980; Ketterer, 1986; Mannervik, 1985). However, as with all other mammalian GSTs that have been examined, the bacterial GSTs we investigated are dimeric proteins in the native state. The mammalian enzymes are composed either of two identical subunits (homodimers) or combinations of two non-identical subunits (heterodimers) (Awasthi \& Singh, 1985; Jakoby \& Habig, 1980; Ketterer, 1986; Mannervik, 1985; Mannervik \& Danielson, 1988). Homodimeric proteins have also been purified from the fungus Mucor javanicus (Ando et al., 1988) and the yeast Issatchenkia orientalis (Tamaki et al., 1989). The GST of Tetrahymena thermophyla, on the other hand, has been reported to be a monomer (Overbaugh et al., 1988).

This paper also shows that bacterial GSTs have characteristics which distinguish them from mammalian GSTs. For example, SDS-PAGE indicates that the subunits of bacterial GSTs are smaller than those of mammalian GSTs. Immunoblotting analysis suggests that the presence of the enzyme we identified as Pm-GST-6.0 (Di Ilio et al., 1988a) is not exclusive to Proteus mirabilis AF 2924, being also present in Proteus vulgaris ATCC 8427, Enterobacter cloacae CIP 6085 and Escherichia coli ATCC 25422. On the other hand, the lack of cross-reaction of GSH-affinity materials from Klebsiella oxytoca CIP 666, K. oxytoca AF 101, Serratia marcescens CIP 6755 and Escherichia coli ATCC 25922 with anti-Pm-GST-6.0 antiserum also suggests the possibility that in bacteria, as in mammals, a wide number of antigenically and structurally different isoenzymes of GST exist. We are currently verifying this hypothesis. The finding that bacterial GST, but not mammalian GSTs, reduces, in vitro, the antimicrobial activity of several classes of antibiotics is of particular interest. It is possible that by binding drugs (the dissociation constants obtained indicate that Pm-GST-6.0 avidly binds antibiotics), bacterial GSTs may represent a defence against the toxic effects of antibiotics.

This work was supported by grants 87.01427 .04 and 89.00200 .70 from the Consiglio Nazionale delle Ricerche (Italy).

\section{REFERENCES}

Ando, K., Honma, M., Chiba, S., Tahara, S. \& Mizutani, J. (1988). Glutathione transferase from Mucor javanicus. Agricultural and Biological Chemistry 52, 135-139.

Awasthi, Y. C. \& Singh, S. V. (1985). Subunit structure of human and rat glutathione $S$-transferases. Comparative Biochemistry and Physiology 82B, 17-23.

BRADFORD, M. M. (1976). A rapid and sensitive method for the quantitation of microgram quantities of protein using the principle of protein-dye binding. Analytical Biochemistry 72, 248-254.

Casalone, E., Di Ilio, C., Federichi, G. \& Polsineli, M. (1988). Glutathione and glutathione metabolizing enzymes in yeasts. Antonie van Leeuwenhoek 54, 367-375.

Chasseaud, L. F. (1979). The role of glutathione and glutathione $S$-transferases in the metabolism of chemical carcinogens and other electrophilic agents. Cancer Research 29, 175-293. 
Clark, A. G., Shamaan, N. A., Sinclair, M. D. \& DAUTERMAN, W. C. (1986). Insecticide metabolism by multiple glutathione $S$-transferases in two strains of the house-fly, Musca domestica (L). Pesticide Biochemistry and Physiology 25, 169-175.

Cochrane, B. J., Morrissey, J. J. \& LeBlanc, G. A. (1987). The genetics of xenobiotic metabolisms in Drosophila. IV. Purification and characterization of the major glutathione $S$-transferase. Insect Biochemistry 17, 731-738.

Del Boccio, G., Di Ilio, C., Alin, P., Jornvall, H. \& MANNER VIK, B. (1987). Identification of a novel glutathione transferase in human skin homologous with Class Alpha glutathione transferase 2-2 in the rat. Biochemical Journal 244, 21-25.

Di Ilio, C., Del Boccio, G., Massoud, R. \& Federici, G. (1986). Glutathione transferase of human breast is closely related to transferase of human placenta and erythrocytes. Biochemistry International 13, 263-269.

Di Ilio, C., Aceto, A., Piccolomini, R., Allocati, N., Faraone, A., Cellini, L., Ravagnan, G. \& FEDERICI, G. (1988a). Purification and characterization of three forms of glutathione transferase from Proteus mirabilis. Biochemical Journal 255, 971-975.

Di Ilio, C., Aceto, A., Del Boccio, G., Casalone, E., Pennelli, A. \& Federici, G. (1988b). Purification and characterization of five forms of glutathione transferase from human uterus. European Journal of Biochemistry 171, 491-496.

HABIG, W. H. \& JAKOBY, W. B. (1981). Assay for differentiation of glutathione $S$-transferases. Methods in Enzymology 77, 398-405.

JAKOBY, W. B. \& HABIG, W. H. (1980). Glutathione transferases. In Enzymatic Basis of Detoxication, vol. 2, pp. 63-94. Edited by W. B. Jakoby. New York: Academic Press.

Kamisaka, K., Habig, W. H., Ketley, J. N., Arias, I. M. \& JAKOBY, W. B. (1975a). Multiple forms of human glutathione $S$-transferases and their affinity for bilirubin. European Journal of Biochemistry 60 , 153-161.

Kamisaka, K., Listowsky, I., Gatmaitan, Z. \& ARias, I. M. $(1975 b)$. Interactions of bilirubin and other ligands with ligandin. Biochemistry 14, 2175-2180.

KetLey, J. N., HABIG, W. H. \& JAKOBY, W. B. (1975). Binding of nonsubstrate ligands to the glutathione $S$-transferases. Journal of Biological Chemistry 250, 8670-8673.

KETTERER, B. (1986). Detoxication reactions of glutathione and glutathione transferases. Xenobiotica 16, 957-973.

Kumagai, H., Tamaki, H., Koshino, Y., Suzuki, H. \& TOCHIKURA, T. (1987). Distribution, formation and stabilization of yeast glutathione $S$-transferase. Agricultural and Biological Chemistry 52, $1377-1382$

LAEMMLI, U. K. (1970). Cleavage of structural proteins during the assembly of the head of bacteriophage T4. Nature, London 227, 680-685.
LaU, E. P., Niswander, L., Watson, D. \& Fall, R. R. (1980). Glutathione $S$-transferase is present in a variety of microorganisms. Chemosphere 9, 565-569.

MANNER VIK, B. (1985). The isoenzymes of glutathione transferase. Advances in Enzymology 57, 357-417.

Mannervik, B. \& Danielson, U. H. (1988). Glutathione transferases. Structure and catalytic activity. Critical Reviews in Biochemistry 23, 281-334.

Mannervik, B., Alin, P., Guthenberg, C., Jensson, H., TAhIR, M. K., WARHOLM, M. \& JoRnVall, H. (1985). Identification of three classes of cytolytic glutathione transferase common to several mammalian species: correlation between structural data and enzymatic properties. Proceedings of the National Academy of Sciences of the United States of America 82, 7202-7206.

Maruyama, H., Inoue, M., ARIAS, I. M. \& LISTOWSKY, I. (1983). The ligandins of glutathione $S$-transferases: a family of multifunctional proteins in the rat. In Functions of Glutathione: Biochemical, Physiological and Toxicological Aspects, pp. 89-97. Edited by S. Orrenius, A. Larsson, A. Holmgren \& B. Mannervik. New York: Raven Press.

National COMmitTeE fOR Clinical Laboratory STANDARDS (1983). Tentative Standard M7-T. Standard Method for Dilution Antimicrobial Susceptibility Tests for Bacteria Which Grow Aerobically. Villanova, Pa., USA : National Committee for Clinical Laboratory Standards.

Overbaugh, J. M., Lau, E. P., Marino, V. A. \& Fall, R. (1988). Purification and preliminary characterization of monomeric glutathione $S$-transferase from Tetrahymena thermophila. Archives of Biochemistry and Biophysics 261, 227-234.

Ramage, P. I. N., Rae, G. H. \& Nimmo, I. A. (1986). Purification and properties of hepatic glutathione $S$ transferases of atlantic salmon (Salmo salar). Comparative Biochemistry and Physiology 83B, 23-29.

Simmons, P. C. \& VAN DER JAGT, D. L. (1981). Purification of glutathione- $S$-transferase by glutathione-affinity chromatography. Methods in Enzymology 77, 235-237.

SMITH, G. J. \& LiTwaCK, G. (1980). Roles of ligandin and the glutathione $S$-transferases in binding steroid metabolites, carcinogens and other compounds. Reviews in Biochemistry and Toxicology 2, 1-47.

Takikawa, H., Sigiyama, Y., Stolz, A., Sugimoto, M. \& KAPLOWITZ, N. (1986). Organic anion-binding by human hepatic GSH $S$-transferases. Biochemical Pharmacology 35, 354-356.

Tamaki, H., Kumagai, H. \& Tochikura, T. (1989). Purification and properties of glutathione transferase from Issatchenkia orientalis. Journal of Bacteriology 171, 1173-1177.

Towbin, H., Staehelin, T. \& Gordon, L. (1979). Electrophoretic transfer of proteins from polyacrylamide gels to nitrocellulose sheets: procedure and some applications. Proceedings of the National Academy of Sciences of the United States of America 76, 4350-4354. 